\title{
Literature Survey of Tritiated Waste Characterization and Disposal (U)
}

\author{
Elliot A. Clark
}

Savannah River Technology Center

Applied Science and Engineering Technology Department

Materials Technology Section

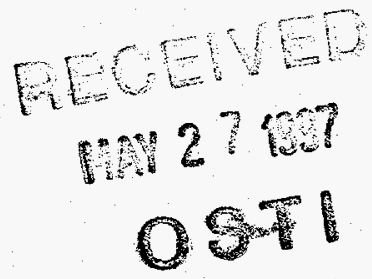

Publication Date: September 6, 1996

\section{Westinghouse Savannah River Company Savannah River Site Aiken, SC 29808}

This document was prepared in connection with work done under Contract No. DE-AC09-89SR18035 with the U. S. Department of Energy. By acceptance of this document, the publisher and/or recipient acknowledges the U. S. Government's right to retain a nonexclusive, royalty-free license in and to any copyright covering this document, along with the right to reproduce and authorize others to reproduce all or part of the copyrighted material. 


\section{DISCLAIMER}

This report was prepared as an account of work sponsored by an agency of the United States Government. Neither the United States Government nor any agency thereof, nor any of their employees, makes any warranty, express or implied, or assumes any legal liability or responsibility for the accuracy, completeness, or usefulness of any information, apparatus, product, or process disclosed, or represents that its use would not infringe privately owned rights. Reference herein to any specific commercial product, process, or service by trade name, trademark, manufacturer, or otherwise does not necessarily constitute or imply its endorsement, recommendation, or favoring by the United States Government or any agency thereof. The views and opinions of authors expressed herein do not necessarily state or reflect those of the United States Government or any agency thereof.

This report has been reproduced directly from the best available copy.

Available to DOE and DOE contractors from the Office of Scientific and Technical Information, P.O. Box 62, Oak Ridge, TN 37831; prices available from (615) 576-8401.

Available to the public from the National Technical Information Service, U.S. Department of Commerce; 5285 Port Royal Road, Springfield, VA 22161. 


\section{DISCLAMIER}

Portions of this document may be illegible in electronic image products. Images are produced from the best available original document. 



\section{ASET}

APPLIED SCIENCE \& ENGINEERING TECHNOLOGY

Keywords: Tritium, Radioactive, Waste, Assay, Storage, Disposal, Decontamination

Retention - Permanent

\section{Literature Survey of Tritiated Waste Characterization and Disposal (U)}

by

Elliot A. Clark

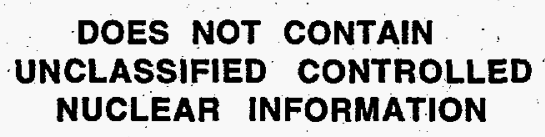

ADC \&

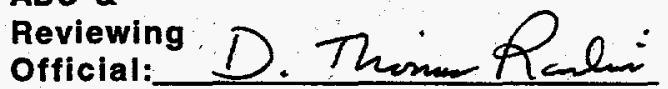

Date: $10122 / 96$

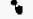

SRTC SAVANNAH RIVER TECHNOLOGY CENTER, AIKEN, SC 29808

Westinghouse Savannah River Company

Prepared for the U. S. Department of Energy under Contract DE-AC09-89SR18035 
WSRC-TR-96-0209

APPROVALS

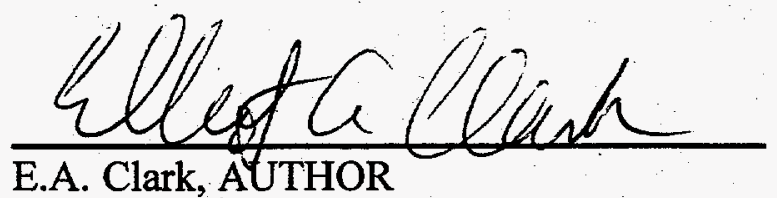

Date: 23 October Gale

Materials Compatibility and Joining Technology Group

MATERIALS TECHNOLOGY SECTION

P.E. Lapp, LECHNICAL REVIEWER

MATERIALS TECHNOLOGY SECTION

Date: $10-23-96$

D. Them Rollin

Date: $10-23-96$

D.T. Rankin, MANAGER

Materials Compatibility and Joining Technology Group

MATERIALS TECHNOLOGY SECTION

T.L. Capeletti, MANAGER MATERIALS TECHNOLOGY SECTION

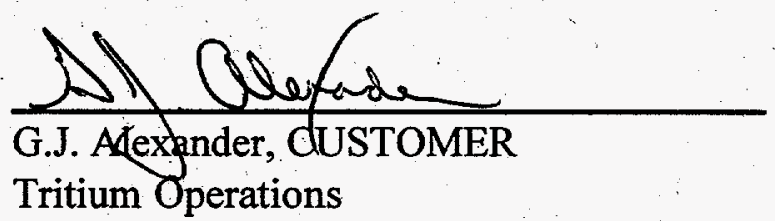

Date: $10 / 30 / 56$

Date: $10-28-96$

ii 


\section{Contents}

Executive Summary 1

Introduction $\quad 2$

Contamination of Materials by Tritium $\quad 2$

Tritium Assay $\quad 5$

Decontamination Methods $\quad 8$

Tritiated Waste Storage and Disposal 11

Recommended Applications at the Savannah River Site 12

References $\quad 13$ 
THIS PAGE INTENTIONALLY BLANK 


\title{
Literature Survev of Tritiated Waste Characterization and Disposal
} (U)

\author{
Elliot A. Clark
}

\section{Executive Summary}

Characterizing, handling, and storing tritiated waste is challenging because of the physical and chemical properties of tritium. Tritium is soluble in many materials, including structural materials such as stainless steel, structural steel, polymers, concrete and paints. Tritium permeates rapidly into these materials compared to other species, and so parts exposed to tritium are normally contaminated to some degree throughout the bulk. The relatively low kinetic energy of the $\beta^{-}$ decay causes detecting tritium anywhere but very near the surface of materials to be impossible, because the $\beta^{-}$particle is absorbed by the material. Tritium readily exchanges with hydrogen in water vapor, and the resulting tritiated water can permeate polymers, concrete, oil, and the oxide surface films normally present on metals. Most of the tritium contamination in structural metals resides in the surface oxide film and in organic films at the surface, when metals are exposed to tritium at ambient temperature and pressure, whether the exposure is to gas or tritiated water.

The most reliable method of assaying tritium is to dissolve samples in a proper liquid scintillant and use $\beta^{-}$scintillation counting. Other methods that require less time or are non-destructive (such as smear/counting) are significantly less reliable, but they can be used for routine waste characterization if sample dissolution/liquid scintillation counting is regularly employed to benchmark them.

Tritiated materials are decontaminated in numerous ways. The most common are flowing moist air, heating, and aqueous detergent and other solvent cleaning. They differ in their ability to decontaminate the surface versus the bulk of materials, as well as the cost and facilities required. Modern methods, such as plasma cleaning and ultraviolet light/ozone cleaning, show promise to decontaminate materials more effectively.

Tritiated water is transported throughout the environment and is easily absorbed by plants and animals, so containing tritiated waste reliably is vital for tritiated waste disposal programs. Tritiated waste storage usually involves segregation by one or more properties including tritium content, tritium offgas rate, material, and source of the waste. Liquid and gaseous tritiated waste is normally converted or fixed to a solid form. Radiolysis can generate significant gas pressure during storage if storage containers are sealed, so either sufficient free volume must exist in containers or the container must vent whatever radiolytic gases are produced.

Based on this literature survey, it is recommended that the following be evaluated at the Savannah River Site: 
1) Existing facilities for sample dissolution and scintillation counting of routine and nonroutine tritiated waste, to determine the need to enhance these facilities,

2) Modern radiological detectors for routine monitoring of waste,

3) New methods of tritium decontamination, including plasma cleaning and ultraviolet light/ozone decontamination.

\section{Introduction}

The physical and chemical properties of tritium make characterizing and disposing of tritium contaminated waste very challenging. Elemental tritium is a gas at ambient temperature, and is therefore very difficult to confine. Extensive and highly reliable gas handling systems are necessary to safely process it. Unlike other radionuclides, gaseous tritium diffuses into solids and liquids it contacts. Tritium isotopically exchanges with protium in water, and tritiated water and water vapor can flow and leach into many materials. Tritiated water (condensed and vapor) is more dangerous than elemental tritium because it is much more easily absorbed by the body. The $\beta^{-}$decay of tritium has a maximum energy of about $18.6 \mathrm{KeV}$ and an average of $6 \mathrm{KeV}$. This relatively low energy is absorbed by very thin layers of matter, which makes assaying it difficult in solids.

This report summarizes a survey of recent literature concerning assaying, decontaminating, and storing tritiated waste. A rather large number of articles in this subject have recently appeared, prompted by the development of experimental fusion power facilities in which tritiated waste is handled $[1,2,3,4,5,6,7,8]$, by facilities that process tritiated heavy water $[9,10,11,12]$, and by decontamination and decommissioning of tritium facilities $[13,14,15]$. Tritium waste disposal

operations are receiving ever increasing scrutiny by various oversight organizations. Currently, waste disposal during operation and decontaminating and decommissioning at the end of facility life must be planned during design of new facilities. Lack of technical knowledge in specific areas of tritiated waste handling is being addressed by applied research around the world.

\section{Contamination of Materials by Tritium}

Tritiated molecular diatomic hydrogen gas, commonly termed "elemental tritium", can be either $\mathrm{HT}, \mathrm{DT}$, or $\mathrm{T}_{2}$, where $\mathrm{H}$ is protium, $\mathrm{D}$ deuterium, and $\mathrm{T}$ is tritium. Tritiated water can be either HTO, DTO, or $\mathrm{T}_{2} \mathrm{O}$, and can be either a condensed liquid or water vapor. Tritiated water and water vapor are also referred to as "tritium oxide" and "oxide".

Hydrogen isotopes readily permeate metals, alloys, polymers, and porous hydrated ceramics such as concrete. Being an isotope of hydrogen, elemental tritium permeates readily from the gas phase into the bulk of many metals [16] and polymers [17]. Tritium is also found near and at the surface of metals, especially in surface oxides that exist on most metals and in surface organic films that cover most parts. Tritiated water vapor cannot permeate or diffuse into metals; however, it can contaminate metal surfaces and can permeate polymers [18], other organics (for 
example, paints [19]) and concrete [18,20]. Most materials in one study absorbed a much greater total activity from atmospheres containing tritiated water vapor (gaseous oxide) than elemental tritium, even if the chemical activity of the elemental tritium (effective pressure) was higher than water [10].

Austenitic stainless steels (for example Types 304L, 316L, and 347) are the materials of choice for tritium processing facilities. These steels are strong, tough, and have good resistance to hydrogen embrittlement. Under the same conditions, hydrogen isotopes permeate austenitic stainless steel to a greater extent than into copper and aluminum, however the mechanical properties, resistance to embrittlement, weldability, and availability of components favor the use of austenitic stainless steels in tritium processing systems. They are also the material of choice for heavy water processing systems and for nuclear facilities.

Most of the total tritium burden of stainless steel exposed to gaseous tritium at ambient temperature and pressure at or below atmospheric resides in the surface oxide layer $[21,22,23]$ or in organic molecules residing on top of the surface oxide $[24,25,26]$. One study showed that there is about 80 times as much tritium at the surface in parts exposed to tritium gas in a tritium handling facility as calculated to be in the bulk [13]. The vast majority of tritium contamination from contact with tritiated water is likewise in surface films. No theory currently exists to calculate the amount of tritium in surface oxides or organic molecules, as there is to calculate the tritium burden in bulk metals. Even if the specific activity (tritium burden per unit volume of a given oxide or organic film) could be calculated, the film thickness must be known to calculate the total tritium burden for a given part [13]. In addition, surface roughness can cause the "effective" surface area to be many times larger than the "geometrical" surface area, and this factor would have to be accounted for in any potential tritium burden calculation [27]. Surface preparation and cleanliness have been shown to significantly influence the amount of contamination on surfaces by tritium gas $[24,27]$.

Thermal desorption spectroscopy is employed to study tritium on metallic surfaces $[21,22,23]$. The temperature of tritium exposed samples is increased at a constant rate and the identity and amount of species that offgas in a specially designed vacuum system are recorded during the experiment [21]. These studies show that most of the tritium offgases as tritiated water vapor at relatively low temperatures (typically between $250^{\circ} \mathrm{C}$ and $400^{\circ} \mathrm{C}$ ). These observations are interpreted to indicate that most of the tritium resides at the surface, bound in surface oxides. The remaining tritium probably resides at various locations in the surface and the bulk, based on the common observation of several peaks of elemental tritiated gas evolution observed in thermal desorption spectroscopy at higher temperatures [23]. The number of tritium atoms on the surface was estimated to be about the same as the number of surface atoms, in one study [22]. At higher temperature, the gas evolved as mainly elemental tritium, but in much smaller amounts than at lower temperature. One study described tritium contamination as being either "weakly" and "strongly" bound [4], which is likely related to the multiple peaks observed in thermal desorption studies. There is evidence that most tritium contamination is bound in the surface oxide on aluminum, similar to stainless steels $[22,23]$. Likewise, it is expected that the surface of most 
metals having appreciable oxide films or organic contamination contains most of the tritium contamination.

The location of tritium in borosilicate glass has been investigated by sequential dissolution [23]. Tritium dissolves in the elemental ( $\mathrm{HT}$ or $\left.\mathrm{T}_{2}\right)$ form. A tritium depleted region exists, in which the tritium concentration is zero at the surface and increases to the bulk concentration at a depth of about 5 microns.

The fraction of the surface tritium on any material that may be transferred by touch is termed "removable". Removable tritium is a radiological hazard for workers, and is the reason why personal protective clothing is worn and glove boxes employed where possible when handling tritiated items [25]. Non-removable tritium contamination, which can be either near the surface or in the bulk, must be accounted for when estimating the total tritium content of parts being disposed of. Surfaces having organic films (such as oil or grease) can accumulate large amounts of tritium; so clean surfaces that are exposed to tritium gas or tritiated water are essential in reducing contamination.

Stainless steel parts that are exposed to tritium gas at elevated temperatures or pressures can contain most of the tritium contamination in the bulk. This occurs because the solubility of tritium in many materials increases with both temperature and pressure and because the amount of tritium in the surface layers is reduced at elevated temperature. In cases where the bulk tritium content is much greater than the surface amount, the tritium concentration can be estimated using solubility and diffusivity data and a finite-difference computer program, if the time, temperature, barrier thickness, and tritium partial pressure are known [28].

Substantially more tritium permeates polymers near ambient temperature under the same conditions than into metals $[16,17,29]$. Unlike in metals, tritiated water is soluble in polymers. (No tritiated water permeates bulk metals; however, tritiated water can react with and enter into the surface oxide as discussed above.) Most polymers are composed of hydrogen atoms attached to carbon polymer chain molecules, and tritium dissolved in either the elemental or aqueous forms can isotopically exchange with hydrogen in the polymer. Because of this exchange, removing dissolved tritium or water vapor under vacuum will not fully decontaminate tritiated polymers. The $\beta^{-}$decay of tritium causes radiation damage of polymers, resulting in either hardening followed by embrittlement or decomposition and degradation [30].

A tritium contamination issue that is discussed in fusion reactor clesign is the concept of "soaking" $[18,19,31,32]$. Soaking refers to tritium permeating the walls of a reactor hall (interior of building surrounding a fusion reactor) after a tritium release into the hall. The amount of time required for a given level of decontamination is significantly longer than that predicted by a model consisting of simple dilution of gaseous tritium by atmosphere exchanges, because the walls that have absorbed tritium or tritiated water during the release offgas slowly compared to the exhcange gas flow rate. Since this type of reactor incident must be anticipated and assessed during design, tritium absorption into construction materials such as concrete, steel, and various types of paint 
has been investigated $[18,19,22,29]$. Concrete is a complex porous material containing significant amounts of hydrogen as either hydroxyl groups, hydrated water, or pore water (condensed water trapped in pores). Because of this, tritium and tritiated water readily permeate concrete and isotopically exchange with all the forms of hydrogen [20]. Concrete is extremely porous, so various surface coatings, such as paints or surface epoxies, are being considered to block the surface pores of concrete and thus reduce the soaking of concrete in reactor halls [18, 19]. Tritium absorption by concrete has been observed to be much greater than that by common paints and other organic coatings [18]. Soaking is related to the observation of re-growth of contamination after surface decontamination, in parts that have been exposed to significant amounts of tritium [32]. The re-growth is simply the continued diffusion of tritium from the material bulk to its surface, which can lead to additional detectable surface contamination.

A recent study indicates that various types of simple organic acids are produced on the surface of stainless steel parts exposed to tritium or tritiated water vapor [26]. The source of the carbon to form these simple organic molecules is uncertain. Possible sources include radiolysis of atmospheric $\mathrm{CO}_{2}$, migration of "dirt" in the facility to the surface, or migration of carbon from the bulk of the steel itself. Attempts to reduce the buildup of hydrocarbons on stainless steel surfaces by cleaning samples and apparatus were unsuccessful in an earlier study [25]. It was previously assumed that tritium off-gassed as water vapor only. These studies reveal that tritium interactions with surfaces are more complicated than previously thought. This phenomenon explain why ionization chambers for tritium detection are difficult to clean and can have significant memory effects.

One study has investigated the contents of oil from vacuum pumps used in tritium service [33]. Various chemical species are found in tritiated oil, including dissolved water, hydrogen, polar additives in the oil (including anti-oxidants, anti-wear agents, and surfactants), volatile and nonvolatile neutral organic molecules, and non-volatile polar organic molecules. Both radiolysis and isotope exchange lead to a tritiated form of these compounds.

\section{Tritium Assay}

The relatively low kinetic energy of the tritium $\beta^{-}$decay means that the $\beta^{-}$particles penetrate only small distances in condensed matter. Because of this, conventional radiation detectors detect only tritium very near the surface, not in the bulk of materials. The most reliable method of assaying tritium is by scintillation counting. This involves dissolving samples in a fluid containing a special scintillating chemical that emits light when $\beta^{-}$decay particles collide with scintillant molecules. Optical detectors count the number of times light is emitted in the solution and thereby measure the total tritium activity of the sample. The average tritium concentration is then calculated from the sample mass or volume before the original dissolution. The method is reliable because the scintillant molecules are within the penetration range of decay $\beta^{-}$particles so that each decay is reliably converted to a light photon that can reach the optical detector and be counted. Scintillation counting has several drawbacks (which include having to obtain a sample of material, destroy the sample, prepare the test by dissolution and mix with the special scintillation 
"cocktail" solution) that make it laborious. These drawbacks cause scintillation counting to be expensive and impractical for regular monitoring of large amounts of tritiated waste.

Cross-contamination is a major problem that leads to erroneous tritium assay results using any method $[9,25]$.

Often tritiated waste items are routinely generated under similar conditions, including temperature, tritium exposure level, and facility location. Because of the prohibitive cost of sampling every item in regular waste streams, and because assaying tritium results in its own waste stream, it is prudent to assert that equivalent exposures of materials result in equivalent tritium concentrations in the same material. If samples of each type of waste have been assayed and it is demonstrated that similar waste streams have similar contamination levels, further assay is redundant. This socalled "process knowledge" can then be used to manifest routine tritiated waste based on prior knowledge of that type of waste article and the facility from which it came [6]. Occasional reassaying can establish firm proof for the assertion that the tritium level of items similarly exposed is the same. A literature survey of integrated exposure of stainless steel to tritium is consistent with this assertion [8].

Radioactive contamination other than tritium on surfaces is commonly sampled by smearing a known area, typically $100 \mathrm{~cm}^{2}$, with paper, and a suitable method assays the activity transferred to the paper. This method is also used for tritiated items because it is rapid, relatively inexpensive, and readily available at nuclear facilities. However, it cannot detect the bulk tritium and non-removable (non-smearable) surface tritium [54]. (The smear paper is immersed in a liquid scintillation cocktail and the smeared tritium migrates into the cocktail.) Successive smears are observed to have reducing tritium activity since smearing cleans the surface, and after a period of time without smearing the activity increases to nearly the original level [24]. The state and cleanliness of the surface drastically influence smear assay of tritium on surfaces [24]. Smears can be made using wet [3,9] or dry [24] paper. Because of these and other known and unknown variables, an "efficiency factor", usually 10 , is invoked and the recorded tritium activity is taken to be efficiency factor times the recorded activity [24]. An improved smearing method involves performing from three to five smears, and then extrapolating the activity back to the hypothetical value before the first smear [24]. This value is less variable than any of the individual smears alone. The efficiency comparing a surface detector and smear samples using the modified multiple smear method varied between $10 \%$ and $50 \%$ [24]. Gas chromatography analysis, instead of scintillation counting, of smear samples has been performed at one facility [9]. The contamination measured on the interior of a glovebox by smearing was found to be related to the glovebox atmospheric tritium content in one study [31].

Other assay methods have been evaluated $[24,35,36,37]$, that are less reliable than scintillation counting for tritium but faster, more convenient, and less expensive. Traditional radiation detectors suffer from the low penetration range of tritium (discussed above), that limits the detectable tritium to that very near the surface [37]. In many cases, the tritium concentration at the surface is greater than the average, and so surface-only detectors do not provide an accurate 
measure of the total bulk tritium concentration. The total tritium concentration must be estimated and recorded for waste disposal. (Measuring removable surface contamination is of course an important and valid radiological protection issue, for both controlling the spread of contamination and protecting against worker uptakes by skin contact.)

Detectors that have been evaluated include those used for other types of $\beta^{-}$contamination detection, and a solid scintillant detector specifically designed for tritium $[24,35,36,37]$. The sensitivity of the detectors evaluated was less than the smear assay, although several showed promise for routine assay [37]. Detectors have been tested either to replace scintillation counting of surface smears (so-called indirect measurement) or to measure tritium surface activity directly [37]. A miniature contact ion chamber detector is being developed for surface contamination [38]. Samples assayed exhibited about five times higher surface activity compared to dry smearing, so the sensitivity of the miniature contact ion chamber appears to be very good.

Assay of process beds can be performed by repeated isotope exchange [14]. The original tritium concentration of beds can be calculated after measuring the amount of tritium removed during each cycle. One study attempted to shorten the time to assay some process beds by measuring the gas flow rates during isotope exchange (swamping) [39]. It was successful for uranium hydride getter beds, but not for molecular sieve beds. The detection level for this technique was 0.10 mole, which is too insensitive for most tritiated waste applications.

A new method involving controlled offgas sampling to infer the bulk tritium concentration in thin organic polymeric waste is being developed [40]. By monitoring the offgas rate of a waste container that has a constant flow of controlled humidity air into the container, a correlation between the measured offgas rate and the total amount of tritium in the container has been found. Permeation of both elemental tritium and tritiated water is rapid in polymers, and after several hours a steady-state flux appears to be established between the inflowing humid air and the total amount of tritium in the container [40]. Seven hours were required to obtain the most reliable offgas estimate. The method has been investigated only for relatively thin polymers to date, representative of normal "job control waste" such as plastic shoe covers, rubber gloves, and other tritium protective clothing items. Another observation made during this study was that tritium can migrate among items within waste containers, in such a manner that a quasi-equilibrium of tritium contamination is established [40]. The total amount of tritium was determined in this study by leaching in an aqueous proprietary solution, based on potassium hydroxide [40]. Leaching in water has also been employed to determine the total amount of tritium in samples [24].

Tritium gas and tritiated water vapor are detected by various types of ion chamber instruments [3, $9,41]$. Great care must be taken to prevent cross-contamination in these detectors, and to reduce memory effects by carefully decontaminating them regularly and when required [9]. The effects of helium, argon, and air carrier gases, and of the humidity of the air carrier gas were determined [???]. Measuring low levels of tritium in a dry air stream caused heavy contamination of the ion chamber, which was then cleaned using a moist air "swamping" treatment [41]. 


\section{Decontamination Methods}

Numerous methods are employed to decontaminate tritium exposed parts. The method chosen depends on the decontamination requirements, available facilities, waste stream limits, and cost.

Chemical hoods and rooms can be decontaminated by flowing moist air through them $[13,31]$. Likewise, closed systems can be decontaminated by repeated cycles of system evacuation and admitting moist ambient air $[3,18]$. This method has the advantage of decontaminating all surfaces accessible to the air. Drawbacks of this method include the tritium release to the environment (when not confined), and its slow speed [32]. Sometimes weeks and months are required to decontaminate rooms to desired levels. Moisture in the air increases the decontamination rate significantly, likely because tritium isotopically exchanges with hydrogen in the moisture and then flows out of the contamination area. Heated air can also increase the decontamination rate [13]. Heating in circulating argon or argon/hydrogen mixture led to a tritium decontamination factor of almost $10^{4}$ at $900^{\circ} \mathrm{C}$, significantly higher than static atmospheres of argon or argon/hydrogen [13]. An electrolysis cell in a tritium system was decontaminated by heating to $350^{\circ} \mathrm{C}$ and cyclically soaking with hydrogen gas and evacuating over a 24 hour period [42]. After one week of repeated soaking with hydrogen and flushing, room air was used as the soak gas. After about 15 days of soaking and flushing, the flush gas contamination level fell to about $0.1 \%$ of its original value. Sometimes, individual parts are so contaminated with tritium that they must be allowed to offgas in a chemical hood for periods of time before they can be safely removed from the hood and processed further. This is especially true for polymer parts.

It is important to remember that tritium decontamination by moist or hot air purging is appropriate for facility surfaces exposed to HT or HTO (for example, glovebox interiors and walls) but does not work for concentrated tritium contamination - in the form of small particles (hydride, spent zeolite), thick metal or polymer objects, and condensed tritiated water. In one case, decontaminating a hood proceeded much more rapidly after a previously unknown source of condensed tritiated water was removed [31].

A portable tritium cleanup system was designed and successfully employed to decontaminate retired tritium facilities with flowing air $[14,43]$. This system includes a bed to catalytically oxidize tritium in the air flow (after removal from the facility walls) and subsequently fix the resulting tritiated water on a molecular sieve dryer. This significantly reduced the tritium release to the environment during decontamination.

External surfaces of metallic parts are routinely decontaminated with common solvents such as alcohol or aqueous detergent or surfactant solutions $[9,14]$. This process produces a tritiated waste stream, which in turn must be disposed of. This method is successful if the contamination resides mainly at the surface, and is removable.

Chemical and electrochemical surface dissolution is another method of decontaminating tritiated parts [25]. Electrochemical dissolution of the surface oxide of stainless steel will successfully 
decontaminate parts exposed at ambient temperature and pressure, since most of the tritium resides in the surface oxide (as discussed above). In one study, a novel method of controlling surface electrochemical potential to not only dissolve the surface but also to diffuse protium from the solution into the surface resulted in significant surface decontamination that was more stable than simply dissolving the surface [44]. This method reduced the rate of re-contamination of the surface, or "retrodiffusion", by tritium diffusion from the bulk $[4,32]$. Electrochemical and chemical dissolution results in a tritiated acidic waste stream, however. Other conductive materials (metals and metallic alloys) can be decontaminated by dissolution if most of the contamination resides at or near the surface. By performing an acid etch after a vacuum bakeout, Type 316 stainless steel was decontaminated by a factor of 200 , much higher than either dissolution (decontamination factor 2) or vacuum-bakeout (decontamination factor 22) used separately.

Parts can be decontaminated by holding the part at elevated temperature $[4,13,21,45]$. Unlike methods discussed above, this method can decontaminate the bulk of the material in addition to the surface. Because of the nature of diffusion in solids, a part must be held at elevated temperature for extended periods to effectively decontaminate the bulk [13]. The time required depends on the thickness of the part and the temperature. One report discusses the concept of "diffusional thickness" of materials, and shows how the exponential temperature dependence of the tritium diffusion coefficient leads to selection of the required decontamination temperature for a given material having a given thickness [41]. It is important to remember that some tritium at or near the surface will offgas and some will diffuse into the bulk when a contaminated part is heated, and so the time required for decontamination to a given level will be longer than the time required to contaminate the surface [13]. In cases of mainly surface contamination, a purely surface decontamination method may therefore be preferable.

Materials can be decontaminated by melting $[45,46,47,48]$. Besides decontamination, this method reduces the volume of waste but requires expensive facilities. The solubility of hydrogen isotopes in stainless steel increases with temperature until the melting point is reached, at which point the solubility increases suddenly by a factor of about three [48]. The solubility increases further with temperature in liquid stainless steel. Because of the increased solubility at elevated temperatures, the largest decontamination factor, defined as the ratio of the initial average tritium concentration to the final tritium concentration, found in one study occurred at between $800^{\circ}$ $1000^{\circ} \mathrm{C}$ [13], well below the melting range of stainless steel, which typically occurs between $1400^{\circ} \mathrm{C}$ and $1450^{\circ} \mathrm{C}$ (Type $304 \mathrm{~L}$ ).

Another possible decontamination and volume reducing method is dissolution in molten metal [47]. This has the advantage of not requiring as high a temperature as melting the part (above). Likewise, it is possible for polymer waste to be incinerated, if the effluent from the incinerator is within local limits or a suitable stripping system is used [47].

Process beds (hydride, getter, etc.), oil, and other items can be decontaminated by isotope exchange $[14,42]$ (which is sometimes termed "isotope swamping" in the literature $[41,47])$. Wet 
degassing (discussed above) is a type of isotope exchange, but intact systems can use a pure protium or deuterium gas stream to exchange with tritium in items being decontaminated. This results in a fairly large amount of tritiated gaseous waste that must subsequently undergo isotope separation to remove tritium from the gas. Normally, approximately ten cycles of exchange are required to significantly decontaminate process equipment. A calculation can be performed to estimate the residual tritium in the bed after the isotope exchanges have been completed [14].

One study used a "dry vapor" technique to decontaminate organic materials [49]. A dry vapor is simply pure water vapor without air, evaporated at sub-atmospheric pressure in a specially designed apparatus. This study found that this new technique decontaminated organic materials faster than a wet air exchange method. The offgas rate of the waste was reduce by 333 times, and the waste decontamination factor was between 1.5 (rubber gloves) and 4 (vinyl).

An ultraviolet source that emits light over a range of wavelengths has been tested to decontaminate tritiated stainless steel surfaces $[25,50]$. Light having $185 \mathrm{~nm}$ wavelength creates ozone from diatomic oxygen, and light having $254 \mathrm{~nm}$ wavelength is absorbed by organic molecules on the surface being decontaminated, resulting in various ions, free radicals, and excited and neutral ions. The ozone combines with volatile molecules to form molecules such as methane, water, and carbon dioxide, which are carried away from the surface species, resulting in decontamination of the surface. The flush gas can be passed through a stripper bed, removing the tritium from the gas and concentrating it on the stripper bed material. Six hours were required to remove $94 \%$ of the tritium on sample surfaces, which corresponds to a decontamination factor of about 17. This method is performed at room temperature, in ambient air.

In another study, a Nd-YAG laser at $532 \mathrm{~nm}$, wavelength removed $90 \%$ of the tritium on a surface after 10 minutes in flowing moist air; $50 \%$ of the tritium was removed as water under the same conditions without the laser light [24]. After 10 minutes, tritium re-deposited on the surface and no further decontamination was observed.

Tritium can also be decontaminated from surfaces by glow discharge, also termed plasma cleaning $[21,25]$. Helium at 0.1 Torr pressure was ionized in a special system, and Type 316 stainless steel disks were decontaminated to a decontamination factor of 250 [21]. These tests were performed in short bursts, to reduce the thermal heating of the sample. The decontamination was therefore caused only by the helium plasma.

Polar solvents have been used to reduce the tritium burden of oils, by removing non-volatile polar tritiated compounds from contaminated oil [33]. Besides reducing the contamination level in the oil, it reduces additional radiolytic gas formation during storage. This method did not reduce the permeation of tritium through waste containers, however.

A new decontamination technique, carbon dioxide pellet cleaning, has been proposed for a new tritium facility [51]. $\mathrm{CO}_{2}$ pellet cleaning is a commercially available process in which a stream of solid $\mathrm{CO}_{2}$ impinges on the surface to be cleaned. After cleaning by abrasion, the $\mathrm{CO}_{2}$ sublimes, 
leaving only the material cleaned from the surface. The potential advantages would be the reduced waste stream resulting from decontamination, and the remote robotic operation of the proposed system. $\mathrm{CO}_{2}$ pellet cleaning has not yet been evaluated for tritium decontamination.

\section{Tritiated Waste Storage and Disposal}

The main goal of any radioactive waste disposal system is to prevent unacceptable contamination of the environment and to protect the health of the public and workers handling the waste by reducing environmental releases and worker exposure to As Low As Reasonably Achievable (ALARA). Radioactive waste storage requirements are determined mainly by responsible regulatory agencies at the waste disposal site. Since tritium can exchange and form water, it is possible for tritium to be transported throughout the environment. Because of this, tritiated waste must be stored in a manner that ensures negligible release to the environment. Often waste is stored in different areas ("segregated") based on the total activity in containers, the origin of the waste, material, offgas rate, or other properties of the waste [2, 45]. A secondary goal is to reduce disposal cost as much as possible. Reducing the volume of tritiated waste, for example by shredding or mechanical compaction $[2,49]$, can reduce the facility cost of disposal. In one case, a database is used to store information about tritiated waste generated [2].

In some facilities, tritiated waste is stored in different areas based on offgas rate $[7,28]$. There may be no requirement for an assay or estimation of the total tritium content of the container. Special systems have been designed to measure the offgas rate of tritiated waste containers $[2,53]$. At Savannah River, and in the United States generally, offgas rates and the total tritium content of each waste container must be estimated. (Transporting tritiated waste in the US also requires manifesting the total tritium content.) As discussed above, tritium permeates the bulk of most materials, and so surface sampling is normally insufficient to measure the total tritium content of unknown tritiated waste. Surface sampling can be used in cases where the surface sample count rate has been correlated with total bulk tritium content in processes that produce similar types of waste.

Tritiated waste can be gaseous, liquid, or solid [11]. The preferred form of long-term waste storage is solid $[2,11]$. Gaseous waste can be oxidized to form tritiated water, or released to the atmosphere, provided the local release limits are not exceeded. Liquids (including tritiated water) can be absorbed by agents to fix the liquid in a solid form [1]. In some cases, solid tritiated waste is assumed to be leachable, that is it is assumed that tritium will spread even if it is in a solid form and no credit is taken for fixing waste as a solid [11]. Because of this, containers of tritiated waste may have specifications for either maximum allowable offgassing or maximum leaching rate. One study showed that sawdust was preferable to other agents testing for fixing liquid tritiated waste [11]. Backfilling a solid waste container with wet sand reduced the tritium release [11]. In Canada, the maximum allowable tritium leaching rate is $10^{-3} \%\left(10^{-5}\right.$ total $)$ per day [11]. To fulfill this criterion, containers of tritiated waste are fabricated from $1 \mathrm{~cm}$ thick high density polyethylene. Polyethylene has a low water permeability among polymers, is readily available, and can be sealed by welding [11]. 
A cross-linked vinyl benzene polymer, termed imbiber beads, has been used to form a fixed gel from tritiated oil [33]. This method can significantly reduce the permeation rate of tritium through the waste container wall. This may allow thinner walled waste containers to be used for tritiated oil storage.

Tritium decay causes radiolysis of species in containers during waste storage $[6,11]$. Pressure buildup from gaseous radiolysis products must be prevented by either ensuring adequate void volume or reducing the amount of tritium in closed containers. Containers allowing sufficient egress of gases to prevent pressure buildup should be used if feasible. An empirical relation was found to predict the pressure buildup in closed containers of tritiated oil given the total activity, temperature, and time in the container [11].

\section{Recommended Applications at the Savannah River Site}

1) Current facilities for sample dissolution/scintillation counting in areas at SRS should be evaluated and upgraded if warranted. The goal should be to have a relatively cost efficient and convenient facility for tritium assay in metals (especially stainless steel), polymers, concrete, oils, and other types of job control and process waste. Each area that generates tritiated waste (for example, Tritium, Heavy Water, Reactors) should either have adequate facilities for assaying tritiated waste samples, or adequate access to another area's assay facility including convenient transportation of radioactive samples. Sample dissolution/scintillation counting would only be used for new or unique articles of tritiated waste, and to benchmark other type of detectors or process knowledge to estimate the tritium content of waste.

2) Modern radiological counting instruments should be evaluated for routine assay of waste. Several instruments have shown promise for improved routine waste assay, if benchmarked with sample dissolution/scintillation counting $[24,35,37]$. In addition, the controlled offgas measurement assay for total tritium in thin polymers inside a container should be evaluated for use at SRS [40].

3) Modern methods of cleaning and decontamination should be evaluated for specific tasks in the SRS Tritium Facilities. Examples of modern methods that could be considered are plasma (glow discharge) cleaning and ultraviolet light/ozone decontamination. If successful, these techniques could speed up operations and reduce the amount tritiated waste. 


\section{References}

1. F. Mannone, H. Dworschak, and G. Vassallo. 'ETHEL's Systems and Facilities for Safe Management of Tritiated Wastes". Fusion Technology 21, March 1992, pp 714-718.

2. G. Newber, A. Haigh, and G. Atkins. "The Handling, Assessment, Transport and Disposal of Tritiated Waste Materials at JET". Fusion Technology 28, October 1995, pp 1552-1557.

3. K Rule, J. Gilbert, G. Ascione, D Birckbichler, S. Elwood, R. Flournoy, J. Stencel, and C. Tilson. "TFTR D-T Experience with Tritium Radioactivity during Maintenance". Fusion Technology 28, October 1995, pp 946-950.

4. A. Tesini, and R. A Jalbert. "Experimental Contamination and Decontamination Studies on JET Remote Handling Tools and Materials when Exposed to Tritium". Report JET-R(88) 18, JET Joint Undertaking, Abingdon, Oxon OX14 3EA, UK, 1988. OSTI Number DE 88706093.

5. R.S. Dickson. "Tritium Interactions with Steel and Construction Materials in Fusion Devices- A Literature Review". Report CFFTP G-9039 (AECL 10208), Canadian Fusion Fuels Technology Project, Ontario Hydro, Mississauga, Ontario, Canada, November 1990. OSTI Number DE 93-613812.

6. D.L. Speed, J.R. Stencel, J.D. Gilbert, R.L Leuenberger, M. Chiruvolu, R.J. Cislo, and L.R. Schroeder. "Tritium Waste Management for TFTR D-T Operations". Fusion Technology 28, October 1995, pp 1566-1571.

7. S.J. Booth and G. Newbert. "Waste Management at JET During Tritium Operations". Fusion Technology 21, March 1992, pp 718-723.

8. P.T. Spampinato, J.C. Commander, G.R. Walton. "Technology Issues for Decommissioning the Tokamak Fusion Test Reactor". Fusion Technolgy 26, November 1994, pp 1030-1033.

9. C.M. Shultz, S.R. Bokwa, R.E. Johnson, and J.M. Miller. "Tritium Monitoring and Analysis in the CRNL Tritium Laboratory". Fusion Technology 14, September 1988, p p 1061-1065.

10. R.S. Dickson and J.M. Miller: "Sorption of Tritium and Tritiated Water on Construction Materials". Fusion Technology 21, March 1992 pp 850-855.

11. J.P. Krasznai, V.S. Chew, and J. Hudson. "Conditionan and Packaging of Tritiated Waste from Ontario Hydro's Tritium Removal Facility". Fusion Technology 21, March 1992, p p 685-690.

12. L.S. Krochmalnek, J.P. Krasznai, and M. Carney. "Conditioning and Handling of Tritiated Wastes at Canadian Nuclear Power Facilities". Report CFFTP-87013, Canadian Fusion Fuels Technology Project, Ontario Hydro, Mississauga, Ontario, Canada, April 1987. OSTI Number DE 89-620093. 
13. V.J. Corcoran, C.A. Campbell, and P.B Bothwell. "Decontamination and Decommissioning of UK Tritium Facilities". Fusion Technology 21, March 1992, pp 727-732.

14. J.L. Maienshein, F. Garcia, R.G. Garza, R.L. Kanna, S.R. Mayhugh, and D.T. Taylor. "Experiences with Decontaminating Tritium-Handling Apparatus". Fusion Technology 21, March 1992, pp 383-388.

15. B.G. Christ and E.L. Wehner. "Decommissioning of NUKEM's Tritium Laboratory". Fusion Technology 21, March 1992, pp 395-400.

16. S.A. Steward. "Review of Hydrogen Isotope Permeability Through Materials". Report UCRL-53441, Lawrence Livermore National Laboratory, Livermore, California, 15 August 1983.

17. S. Pauly. "Permeability and Diffusion Data", chapter VIl in Polymer Handbook $3^{\text {rd }}$ Edition, ed. J. Brandrup and E.H. Immergut, Wiley-Interscience 1989, pp 435-449.

18. F. Ono, S. Tanaka, and M. Yamawaki. "Sorption of Tritiated Water on Organic Materials and Subsequent Desorption". Fusion Technology 21, May 1992, pp 1964-1967.

19. F. Ono, S. Tanaka, and M. Yamawaki. "Sorption and Desorption of Tritiated Water on Paints" Fusion Technology 21, March 1992, pp 827-832.

20. S. Numata, Y. Fujii, and M. Okmoto. "Evaluation of Tritiated Water Retention Capacity of Fusion Reactor Concrete Building". Fusion Technology 21, March 1992 pp 821-826.

21. A.B. Antoniazzi, W.T. Shmayda, and R.A. Surette, "Decontamination of Stainless Steel". Fusion Technology 21, March 1992, pp 867-871.

22. N.M. Masaki, T. Hirabayashi, and M. Saeki. "Study on Sorption of Tritium on Various Material Surfaces and its Application to Decontamination of Tritium-Sorbing Materials". Fusion Technology 15, March 1989, pp 1337-1342.

23. M. Saeki, T. Hirabayashi, Y. Aratono, M. Nakashima, N.M. Maski, and E. Tachikawa. "Chemical Behavior of Tritium In/On Various Materials". Fusion Technology 21, March 1992, pp 806-811.

24. L. Rodrigo, M.J. Ivanco, J.W. Goodale, J.A. Senhrabek, L.K. Jones, and L.M. Phillipi. "Measurement of Tritium on Surfaces", Fusion Technology 28, October 1995, pp 940-945.

25. P Agg, A.B. Antoniazzi, B. Fishbein, J.P. Krasznai, R.E. Massey, and R. Mowat. "Low Temperature Characterization of Tritium Contaminated Surfaces Used in Animal Studies". Fusion Technology 28, October 1995, pp 1097-1102.

26. Y. Belot, H. Camus, S. Raviart, A.B. Antoniazzi, and W.T. Shmayda. "Production of Tritiated Organic Acids at Tritium-Bearing Stainless Steel Surfaces Exposed to Air". Fusion Technology 28, October 1995, pp 1138-1143.

27. J.T. Gill, W.E. Moddeman, and R.E. Ellefson. "Chemically Polished Stainless Steel Tubing for Tritium Service”. J. Vac. Sci. Technol. A 1 (2), Apr.-June 1983, pp 869-873.

28. J.Crank. "Mathermatics of Diffusion". University Press, Oxford, UK (1964). 
29. C. Housiadas and K. Douglas. "Experimental and Modeling Studies on the Exposure of Wall Surfaces to Tritium Gas in Ambient Room Conditions". Fusion Technology 28, October 1995, pp 871-876.

30. D.C. Phillips. "Effects of Radiation on Polymers". Materials Science and Technology 4 , January 1988, pp 85-91.

31. C.L. Sienkiewicz. "Tritium Surface Contamination" Fusion Technology $\underline{8}$, September 1985 , pp 2444-2454.

32. F. Ono, M. Yamawaki, and S. Tanaka. "Regrowth of Tritium Release from Tritium Contaminated Materials". Fusion Technology 28, October 1995, pp 1250-1255.

33. J.P. Krasznai, D.F. Mullins, and R.A. Mowat, "Tritiated Waste Management - Tritiated Oil Packaging and Decontamination." Fusion Technology 28, October 1995, pp 1540-1545.

35. G.D. Whitlock. "Tritium Surface Contamination Measurements with International Credibility", Fusion Technology 21, March 1992 pp 523-528.

36. G.D Whitlock. "A Large Area Tritium Standard Source for Traceable Calibration of Surface Contamination Monitors", Fusion Technology 21, March 1992 pp 462-464.

37. R.A. Surette and M.J. Wood. "An Evaluation of Instruments and Techniques for Monitoring of Tritium Contaminated Surfaces". Fusion Technology 28, October 1995, p p 957-963.

38. N.P. Kherani and W.T. Shmayda. "Ionization Surface Activity Monitor for Tritium". Fusion Technology 28, October 1995, pp 893-898.

39. R.E. Ellefson, C.N. Lindsay, and E.E. Johns. "Measurement and Prediction of Tritium Holdup". Fusion Technology 14, September 1988, pp 1036-1040.

40. A.B. Antoniazzi and W.T. Shmayda. "Assessment of Tritium Inventory in Waste by Outgassing Measurements". Fusion Technology 28, October 1995, pp 1457-1462.

41. L. Rodrigo, J.M. Miller, S.R. Bokwa, R.E. Hohnson, B.M. BacDonald, and J. Senohrabek. "Tritium Measurement and Monitoring in Experiental and Process Systems with Ionization Chambers". Fusion Technology 21, March 1992, pp 629-635.

42. J. Barnes, W. Harbin, J. Anderson, J. Bartlit, T Hayashi, H. Nakamura, M. Inoue, K. Hirata, K. Okuno, and Y. Naruse. "Experience with Maintenance of a Tritium Containatied Test Component at TSTA". Fusion Technology 21, May 1992 pp 1984-1986.

43. J.L. Maienshein, S.W. Wilson, and F. Garcia. "Design and Operational Experience with a Portable Tritium Cleanup System". Fusion Technology 21, March 1992, pp 691-695.

44. G. Bellanger. "Stainless Steel Electrochemical Behaviour - Application to the Decontamination of Steel Parts Contaminated by Tritium", Report CEA-R-5561, Centre d'Etudes de Valduc, Commissariat à l'Energie Atomique, Saclay, France (in French), March 1991. OSTI Number DE 91-502408. 
45. P. Giroux, Th. Pelletier, and M. Maj. "Strategy for Management of Solid Tritiated Wastes". Fusion Technology 21, March 1992, pp 706-713.

46. R.A.H. Edwards and P. Pacenti. "Apparatus for Studying Tritium Recovery from Hard Waste". Fusion Technology 28, October 1995, pp 1478-1484.

47. R.A.H. Edwards. "Issues in Tritiated Waste Management for Fusion Power Reactors". Fusion Technology 28, October 1995, pp 1472-1477.

48. E.A. Clark. "Decontaminating and Melt Recycling Tritium Contaminated Stainless Steel". Report WSRC-TR-95-0160, Westinghouse Savannah River Company, Aiken, South Carolina, 3 April 1995.

49. Th. Pelletier, P. Giroux, and M. Maj. "Reprocessing of Tritiated Organic Products". Fusion Technology 21, March 1992. pp 560-565.

50. J.P. Krasznai and R. Mowat, "UV/Ozone Treatment to Decontaminate Tritium Contaminated Surfaces". Fusion Technology 28, October 1995, pp 1336-1341.

51. J.M. Mintz, T.C. Reitz, and M.T. Tobin. "National Ignition Facility Environmental Protection Systems". Fusion Technology 26, November 1994, pp 1003-1008.

52. Ph. Paillard and H. Clerc. "Low Level Tritium Waste Management and Associated Controls at Bruyeres Le Chatel Research Center". Fusion Technology 21, March 1992, pp 696-699.

53. W. Bramy, B. Hircq, M. Peyrat, Ph. Paillard, and F. Mannone. "Measurement of Low Level Gas Release Rates Applied to Tritiated Wastes", Fusion Technology 21, March 1992, pp 724-726.

54. R.P. Fischer and M. Mintz. "LLNL and DOE Collaborate on Successful Fusion Facility Cleanup". Science \& Technology Review, Lawrence Livermore National Laboratory, Livermore, California, June 1996, pp 14-19. 